\title{
Estimation of the age of senegalese children based on panoramic radiography of the third mandibular molar
}

\author{
Mamadou Lamine Ndiaye ${ }^{1, *}$, Sankoug Soumboundou ${ }^{2}$, Mamadou Tidiane Diallo ${ }^{3}$, Mohammed Taha \\ Mokssite $^{4}$, Babacar Toure ${ }^{5}$ \\ 1,2,3,5 Assistant Professor, ${ }^{4}$ DDS, Dept. Of Odontology, Cheikh Anta Diop University of Dakar, Senegal
}

*Corresponding Author:

Email: mlndiaye04@gmail.com

\begin{abstract}
Introduction : The objective of this preliminary study was to evaluate the interest of the third molar in the determination of the age of Senegalese subjects by the Demirjian method.

Materials and Methods: This is a descriptive cross-sectional study of digital panoramic x-rays of Senegalese patients, aged 5 to 24 years. The statistical analysis was performed with the SPSS software. The significance threshold was less than 0.05 ( $<<0.05$ ).

Results: Of the patient radiographs explored, 283 met the selection criteria. The sample selected consisted of 52\% ( $\mathrm{n}=146$ ) boys and $48 \%(n=137)$ girls. Germination of the third mandibular molar began at an average age of $7.21 \pm 1.64$ years in boys and $7.71 \pm$ 3.71 years in girls. Apical closure occurs at 20.11 \pm 2.89 years and $20.70 \pm 2.73$ years for boys and girls, respectively.

Conclusion: This preliminary study shows the interest of the use of the third molar in the estimation of age in the Senegalese population. A radiographic study of the third molar on the determination of the civil age, with a representative sample of African subjects aged between 14 and 22 years proves necessary.
\end{abstract}

Keywords: Chronologic age, Dental age, Third molar, Panoramic Radiographic, Demirjian method, Senegaleses.

\section{Introduction}

In sub-Saharan Africa, 64 per cent of births are not registered. ${ }^{1}$ The consequences for children can be immense. In the absence of documents proving their age, these children do not possess birth certificates, which should open the door to a whole series of other rights. ${ }^{1,2,3}$

For a minor, being wrongly identified as an adult can have irreversible consequences on his or her life, whereas he or she should benefit from considerations regarding his or her abilities and maturity, guarantees of respect for his or her rights. Therefore, when the State or other bodies need to know the age of a child without a civil status, various methods can be used. The dental age that can be inferred from the stages of dental maturation is accepted as a reliable indicator in estimating the civil age of children whose date of birth is unknown. ${ }^{4-8}$

However, conversion to civilian age may vary among populations. ${ }^{9}$ The third molar is of particular interest because it is the last to form, as it is the only tooth that completes its formation after pubertal age, which proliferates an important place in forensic medicine and legal as an important element of estimation of chronologic age. ${ }^{11}$ However, few studies have been carried out on the interest of the third molar in estimating the age of African subjects. ${ }^{12,13}$ The objective of this preliminary study was to evaluate the interest of the third molar in the determination of the age of Senegalese subjects in panoramic radiography digitized by the Demirjian method.

\section{Materials and Methods}

This is a descriptive cross-sectional study of digital panoramic X-rays of Senegalese patients taken in 201 at a medical imaging centre in Dakar. Patients were referred by dentists. All radiographs were performed on the same device, NEWTOM GIANO and by the same experienced operator.

The study included radiographs of patients aged 5 to 25 years. The patients were free of developmental pathology, the exact date of birth of the patient was known, with the presence of at least a third healthy mandibular molar.

The radiographic images had an optimal legibility with a good contrast, the date of realization known, without infectious or tumour pathology present.

A dental surgeon specializing in dento-maxillofacial radiology had explored the radiographs. The evaluation methodology was standardized. The films were examined on a computer screen in JPEG format (Joint Photographic Experts Group). The examiner had initially participated in a calibration that consisted of analyzing 30 radiographs. At an interval of one week 15 randomly selected panoramic radiographs were reassessed to calculate intra-examiner reproducibility.

To simplify the presentation of this study, the scores obtained were presented for a single tooth, tooth 38 (third lower left molar). The radiographs were classified according to the 8 stages of mineralization of the $3 \mathrm{rd}$ molar according to the Demirjian method (Table I). ${ }^{7}$ The subject's civil age was determined by differentiating between the date the panoramic x-ray was taken and the patient's date of birth.

The statistical analysis was performed using the SPSS software (Statistics Package for Social Science version 20.0). The Kappa coefficient was used to assess the inter-examiner agreement. Qualitative variables were expressed as percentages and quantitative variables as 
means \pm standard deviation. The chi-square test was used to assess the association between qualitative and quantitative variables. The correlation between chronological and dental ages was assessed by the Rho Spearman test. The significance threshold was set at 0.05 .

\section{Results}

Of the 994 patient radiographs explored, 283 met the selection criteria.

The selected sample consisted of $52 \% \quad(n=146)$ panoramic radiographs of boys and $48 \%(n=137)$ of girls. For the intra-examiner agreement, the kappa value was 0.89 (good agreement).

Table II shows the distribution of the workforce by stage of maturity. Stage D (Fig. 1) was more representative with $33 \%(n=94)$ followed by stage 0 (Fig. 2) with $21.9 \% \quad(n=62)$. Germination of the third mandibular molar began at an average age of $7.21 \pm 1.64$ years in boys (Table II) and $7.71 \pm 3.71$ years in girls. Apical closure (Fig. 3) occurs at 20.11 2.89 years and $20.70 \pm 2.73$ years for boys (Table II) and girls (Table III), respectively.

The Rho and Spearman test shows a strong correlation between chronological age and dental age, p l'âge.05 with $\mathrm{r}=0.804$ in girls and $\mathrm{r}=0.894$ in boys (Table V).

Table I: Schematic drawings and brief description of stages of crown and root formation used to score third molar development (modified Demirjian et. al. method)

\begin{tabular}{|c|c|c|}
\hline Stage & Radiographic appearance & Description of stage \\
\hline Stage 0 & & Crypt outline visible. No calcification \\
\hline Stage A & & Calcification of single occlusal points without fusion of different calcifications \\
\hline Stage B & & Fusion of mineralization points; the contour of the occlusal surface is recognizable \\
\hline Stage C & & $\begin{array}{l}\text { Enamel formation has been completed at the occlusal surface and dentine formation has } \\
\text { commenced. The pulp chamber is curved and no pulp horns are visible }\end{array}$ \\
\hline Stage D & & $\begin{array}{l}\text { Crown formation has been completed to the level of the Enamelocemental junction. Root formation } \\
\text { has commenced. The pulp horns are beginning to differentiate, but the walls of the pulp chamber } \\
\text { remain curved }\end{array}$ \\
\hline Stage $\mathrm{E}$ & & $\begin{array}{l}\text { The root length remains shorter than the crown height. The walls of the pulp chamber are straight } \\
\text { and the pulp horns have become more differentiated than in the previous stage. In molars, the } \\
\text { radicular bifurcation has commenced to calcify }\end{array}$ \\
\hline Stage F & & $\begin{array}{l}\text { The walls of the pulp chamber now form an isosceles triangle and the root length is equal to or } \\
\text { greater than the crown height. In molars the bifurcation has developed sufficiently to give the } \\
\text { roots a distinct form }\end{array}$ \\
\hline Stage G & & $\begin{array}{l}\text { The walls of the root canal are now parallel, but the apical end is partially open. In molars only } \\
\text { the distal root is rated }\end{array}$ \\
\hline Stage $\mathrm{H}$ & & $\begin{array}{l}\text { The root apex is completely closed (distal root in molars). The periodontal membrane surrounding } \\
\text { the root and apex is uniform in width throughout }\end{array}$ \\
\hline
\end{tabular}

Table II: Distribution of the sample according to the stages of maturation of the 38

\begin{tabular}{|l|c|c|c|}
\hline Stage & Females & Males & Total \\
\hline 0 & 28 & 33 & 62 \\
\hline A & 15 & 8 & 23 \\
\hline B & 8 & 12 & 20 \\
\hline C & 8 & 17 & 25 \\
\hline D & 51 & 43 & 94 \\
\hline E & 6 & 8 & 14 \\
\hline F & 7 & 6 & 13 \\
\hline G & 5 & 12 & 17 \\
\hline H & 8 & 7 & 15 \\
\hline Total & 137 & 146 & 283 \\
\hline
\end{tabular}


Table III : Mean ages of males by maturation stage of tooth 38

\begin{tabular}{|l|c|c|c|c|}
\hline \multicolumn{1}{|c|}{ Stage } & Mean & Ecart-type & Minimum & Maximum \\
\hline 0 & 7.21 & 1.64 & 5.05 & 12.22 \\
\hline A & 8.02 & 0.87 & 6.62 & 9.02 \\
\hline B & 9.21 & 1.22 & 7.19 & 11.37 \\
\hline C & 10.06 & 1.34 & 8.19 & 12.79 \\
\hline D & 11.82 & 1.76 & 6.97 & 15.50 \\
\hline E & 14.39 & 1.27 & 12.23 & 16.12 \\
\hline F & 15.87 & 1.20 & 13.71 & 17.04 \\
\hline G & 16.10 & 1.36 & 13.03 & 17.85 \\
\hline H & 20.11 & 2.89 & 16.52 & 23.95 \\
\hline
\end{tabular}

$* \mathrm{CI}=95 \%$ confidence interval for mean

Table II : Mean ages of females by maturation stage of tooth 38

\begin{tabular}{|l|c|c|c|c|}
\hline Stage & Mean & Ecart-type & Minimum & Maximum \\
\hline 0 & 7.71 & 3.71 & 4.12 & 13.53 \\
\hline A & 8.61 & 1.01 & 6.41 & 9.92 \\
\hline B & 10.12 & 1.51 & 8.76 & 13.66 \\
\hline C & 10.29 & 0.79 & 9.23 & 11.45 \\
\hline D & 11.72 & 1.86 & 7.17 & 15.30 \\
\hline E & 14.81 & 2.48 & 12.16 & 18.56 \\
\hline F & 15.04 & 1.01 & 13.31 & 16.27 \\
\hline G & 17.59 & 3.22 & 14.53 & 21.41 \\
\hline H & 20.70 & 2.73 & 17.14 & 23.88 \\
\hline
\end{tabular}

$* \mathrm{CI}=95 \%$ confidence interval for mean

Table V: Correlation of maturation stage with civil age

\begin{tabular}{|l|c|c|}
\hline & Females & Males \\
\hline Rho de Spearman & 0,804 & 0,894 \\
\hline p-value & 0,00001 & 0,00001 \\
\hline
\end{tabular}

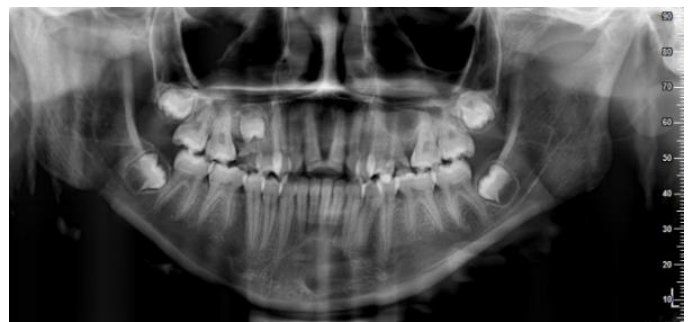

Fig. 1 : Digital panoramic radiograph showing the third left mandibular molar (38) at stage D

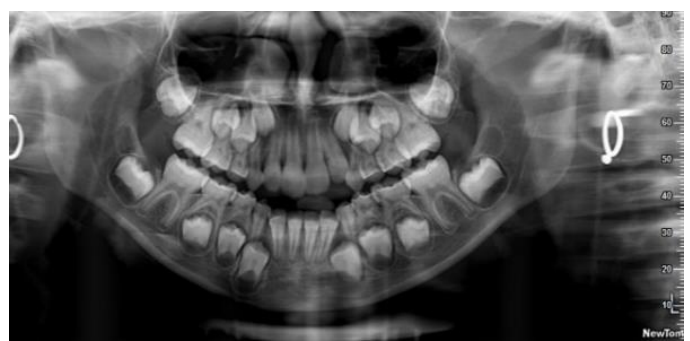

Fig. 2: Digital panoramic radiograph showing the third left mandibular molar (38) at stage 0

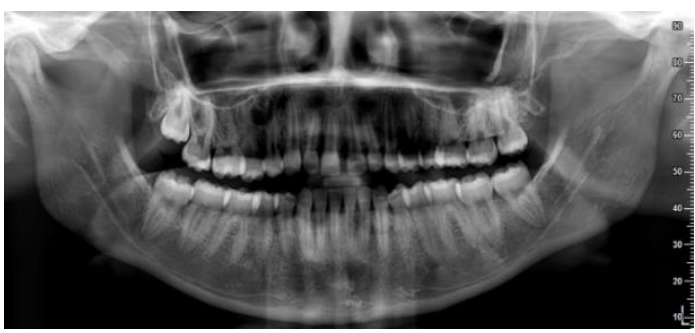

Fig. 3: Digital panoramic radiograph showing the third left mandibular molar (38) at stage $H$

\section{Discussion}

This study focused on radiographic analysis of the coronary and root edification of the third left mandibular molar, on digital panoramic radiography. Panoramic radiography is the most widely used complementary examination in dento-maxillary anatomical exploration in dentistry. It allows a global vision of the anatomical structures of the facial massif on a spread out plane. ${ }^{14}$ Because of the difficulties related to the superimposition of anatomical structures such as the sinus wall, the zygomatic arch and the radiographic artefacts of the upper air-digestive pathways, the third maxillary molars were chosen. This may therefore limit the forensic use of the third molar to estimate the legal age. A larger sample size will be required to draw conclusions.

In the present study, a significant correlation between dental age and chronological age was found for men and women, whit $r=0.89$ for men and $r=0.80$ for 
women, to the results of some authors on the same subject. $^{10,15}$ The intra-examiner reliability was high, which reduced the downside associated with the results and their interpretation. This confirms the reliability of Demirjian's method ${ }^{7}$ by its ease of use and reproducibility.

Age determination is an important criterion in judicial cases. Indeed the proceedings are different according to the age of the subject. ${ }^{4,13,14,15}$ The most widely used method of determining dental age is the one described by Demirjian. ${ }^{7}$ The third molar has an interest in estimating age because it is the last tooth to finish its evolution. This study on Senegalese subjects (137 girls or $48 \%, 146$ boys), shows the interest of panoramic radiography of the third molar in estimating the age of populations. The results showed that the third began its construction at $7.2 \pm 1.64$ years and $7.7 \pm 3.71$ years and ended at $20.11 \pm 2.8$ years and $20.70 \pm 2.7$ years respectively for men and women. According to Mohammed RB et $\mathrm{al}^{10}$ of 330 Indian subjects, the development stages of the third mandibular molar in men begin at 9 years of age and root completion at 18.9 years of age and in women at 9 and 18.6 years of age respectively. This shows that women reach the majority slightly earlier than men. The formation of the third molar of the Senegalese populations is rather compared to the Indian ${ }^{10}$ and Saudi ${ }^{16}$ population.

Stage A in Saudi men occurred at age 13.29, compared to 8.02 in this study. Stage B ( Fig. 4) is 10.1 years \pm 1.51 years on average in female and male subjects, which is lower than that found in similar studies which showed values of 14.5 and 14.6 years respectively in Germany ${ }^{17} 14.2$ years and 13.9 years in Turkey. ${ }^{15}$

This study shows that the Senegalese subjects who were in stage $\mathrm{H}$ (Table I), with at the end of the root construction of the third molar, were over 18 years of age, and were therefore adults. However at almost 18 years the girls were in stage $\mathrm{G}$.

This civil majority was more observed at stage $\mathrm{E}$ in the German population, ${ }^{17}$ at stage $\mathrm{G}$ for Turks, ${ }^{15}$ Indians ${ }^{7,10}$ and Malaysians. ${ }^{18}$ The socio-economic level as well as ethnic and geographical origins could explain these differences.

\section{Conclusion}

This preliminary study shows the interest of the use of the third molar in the estimation of age in a Senegalese population. The estimated dental age should not be restricted to a single estimation technique, but different techniques available will have to be applied, measurements made and repetitive calculations made to establish several reproducibilities. A radiographic study of the third molar on the determination of the civil age, with a representative sample of African subjects aged between 14 and 22 years proves necessary.

\section{References}

1. UNICEF. Fonds des nations unies pour l'enfance, l'enregistrement à la naissance: Un droit pour commencer. Series Digest Innocenti, 2002, 9:3.

2. Gleissner C. Usefulness of combining clinical and radiological dental findings for a more accurate oninvasive age estimation. J Forensic Sci 2007;52:146-50.

3. Eid RM, Simi R, Friggi MN, Fisberg M. Assessment of dental maturity of Brazilian children aged 6 to 14 years using Demirjian's method. Int J Paediatr Dent 2002;12:423-8.

4. Chaillet N, Willems G, Demirjian A. Dental maturity in Belgian children using Demirjian's method and polynomial functions: New standard curves for forensic and clinical use. J Forensic Odontostomatol 2004;22:18-27.

5. Raut DL, Mody RN. Radiographic evaluation of cervical vertebrae, carpal metacarpal bones and mandibular third molar during adolescence and in young adults. J Indian Acad Oral Med Radiol 2006;18:24-9.

6. Rai B, Anand S. Age estimation in children from dental radiograph: Are gression equation. Internet J Biol Anthropol 2008;1:2.

7. Demirjian and A et Goldstein H. New systems for dental maturity based on seven and four teeth. Ann Hum Biologie 1976,3:411-21.

8. Ngom PI, Faye M, Ndoye Ndiaye F, Yam AA, Diagne F. Applicabilité des standards de maturation dentaire de Demirjian chez des enfants sénégalais. Dakar Med, 2007;52:196-203.

9. Mohammed RB, Koganti R, Kalyan SV, Tircouveluri S, Singh JR, Srinivasulu E. Digital radiographic evaluation of mandibular third molar for age estimation in young adults and adolescents of South Indian population using modified Demirjian's method. J Forensic Dent Sci. 2014;6(3):191-6.

10. Thevissen PW, Pittayapat P, Fieuws S, Willems G. Estimating age of majority on third molars developmental stages in young adults from Thailand using a modified scoring technique. J Forensic Sc 2009;54:428-32.

11. Kasper KA, Austin D, Kvanli AH, Rios TR, Senn DR. Reliability of third molar development for age estimation in a Texas Hispanic population: A comparison study. $\mathrm{J}$ Forensic Sci 2009;54:651-7.

12. Liversidge HM, Peariasamy K, Folayan MO, Adeniyi AO, Ngom PI, Mikami Y, Shimada Y, Kuroe K, Tvete IF, Kvaal SI. A radiographic study of the mandibular third molar root development in different ethnic groups. J Forensic Odontostomatol. 2017 1;2(35):97-108.

13. Cavrić J, Galić I, Vodanović M, Brkić H, Gregov J, Viva S, Rey L, Cameriere R. Third molar maturity index (I3M) for assessing age of majority in a black African population in Botswana. Int $\mathrm{J}$ Legal Med. 2016;130(4):1109-20.

14. Foucart JM, Felizardo R, Pizelle C, Bourriau J. Indications for radiography in orthodontics and dentofacial orthopedics. Orthod Fr. 2012;83(1):59-72.

15. Orhan K, Ozer L, Orhan AI, Dogan S, Paksoy CS Radiographic evolution of third molar development in relation to chronological age.among Turkish children and youth. Forensic Sci Int. 2007;165:46-51.

16. Ajmal M, Assiri KI, Al-Ameer KY, Assiri AM, Luqman M. Age estimation using third molar teeth: A study on southern Saudi population. J Forensic Dent Sci. 2012;4(2):63-5.

17. Olze A, Bilang D, Schmidt S, Wernecke KD, Geserick G, Schmeling A. Validation of common classification 
systems for assessing the mineralization of third molars. Int J Legal Med, 2005,119:22-6.

18. Johan NA, MF Khamis, Abdul Jamal N.-É., Ahmad B, Mahanani ES. La variabilité du développement de la troisième molaire inférieure dans la population malaisienne du Nord-Est avec application à l'estimation de l'âge. J Odontostomatol médico-légal . 2012;30(1):4554. 